\title{
Depression and Anxiety
}

SHORT COMMENTARY

\section{The Health Effects of the Abuse of Ketamine}

William J Maloney*

Clinical Associate Professor, Department of Cariology and Comprehensive Care, New York Univeristy College of Dentistry, USA

*Corresponding author: William J Maloney, DDS, Clinical Associate Professor, Department of Cariology and Comprehensive Care, New York Univeristy College of Dentistry, USA

\begin{abstract}
Ketamine is a dissociative anesthetic which is used in powdered or liquid form. A number of individuals have abused this drug or have been instrumental in others using this drug as a "date-rape" drug. Abuse of ketamine can result in a number of systemic manifestations including gastrointestinal issues, depression, and respiratory problems and amnesia. Serious debilitating urinary tract symptoms are also seen frequently in those individuals who abuse ketamine.
\end{abstract}

\section{Keywords}

Ketamine, Anesthetic, Phencyclidine, Delirium, Hallucinations, Depression, Psychedelic, Addiction

\section{Introduction}

Addiction is defined as being a primary chronic disease of the brain reward, motivation, memory in this complex circuitry. A dysfunction in this complex circuitry can lead to certain manifestations in an individual [1]. The individual who suffers from addiction does not have the ability to abstain from this harmful pursuit and, as a result, addiction can take control of one's life. Ketamine, an anesthetic which, has provided much needed relief of pain in medical surroundings, has been subject to abuse by individuals leading to their dependence of this drug. Ketamine is used in the treatment of chronic and acute pain in adults and children [2]. Like all forms of addiction it is imperative that the substance-abusing individual seek professional counselling and treatment immediately in an attempt to break the powerful bonds of addiction.

Ketamine is a dissociative anesthetic which means that it distorts the perception of sight and sound while producing a feeling of detachment from one's self and surroundings [3]. It is known by a number of street names such as Special K, Green K, Super K, Super acid, Jet, and Cat Valium [3]. Ketamine has also been known as a psychedelic club drug and a date-rape drug due to its ability to quickly numb and render an individual immobile. Ketamine's use as a "club drug" rose in popularity during the 1990s. When used as a recreational drug ketamine can produce delirium, a slowed perception of time and altered states of consciousness [4]. Recent studies indicate that ketamine might have the ability to aid in the treatment of severe depression [5]. Ketamine is considered to be safe for pain relief and sedation even in those intensive care patients who are experiencing cardiovascular instability [6] as ketamine is able to provide anxiolysis while maintaining cardiovascular stability [7].

Accidental overdose is fairly common as some users underestimate its potency. It can be taken in pill form or smoked but, it is usually injected or snorted. Ketamine may be administered orally, rectally, intranasally, IV, IM, or intrathecally [8].

Ketamine was first synthesized at Parke-Davis Company in 1962 by Alvin Stevens and was first used in humans by Corssen and Domino in 1965 [9].

The Mechanism of action of ketamine, which is lipid and water soluble [10], is the noncompetitive antagonism of the n-methyl-D-aspartic acid receptor [11,12]. Ketamine shows a chiral structure which consists of two optical isomers and undergoes oxidative metabolism primarily due to norketamine by cytochrome P450 (CYP) 3A and CYP2B6 enzymes [13]. Ketamine acts as a non-competitive antagonist of glutamatergic $\mathrm{N}$-methyl-D-aspartate (NMDA). This results in chang- 
es in synaptic and cellular plasticity via local glutamate non-NMDA-receptors [14].

The abuse of ketamine may lead to a syndrome of cystitis and contracted bladder. Also, abusers often suffer secondary renal damage resulting in these individuals becoming dependent on dialysis $[15,16]$. Another frequent presentation in ketamine abusers is upper gastrointestinal symptoms [17].

The recreational use of ketamine results in a number of central nervous system effects such as floating sensations, alterations in body image and mood, drowsiness, vivid dreams, delirium, and hallucinations [18-20]. Individuals who abuse ketamine have been reported to binge on ketamine which is a behavior frequently seen in cocaine addicts [21]. If the ketamine user is mixing ketamine with other drugs or alcohol, a ketamine overdose may result with only a very small amount of ketamine [22]. Frequent users of ketamine have exhibited disturbances in verbal memory. These individuals may experience difficulty in remembering conversations and people's names [23].

The usual illicit dose of ketamine ranges from 50 $\mathrm{mg}$ to $100 \mathrm{mg}$ [24-26]. Acute toxic effects of ketamine abuse include tachycardia, cognitive dysfunction, abdominal pain, muscle rigidity, hypertension and raised intracranial pressure with death being the end result at times $[27,28]$. Cholestasis has also been linked to chronic ketamine abuse $[29,30]$. Cholestasis is a reduction or stoppage of bile flow from the liver to the duodenum.

Ketamine withdrawal symptoms are usually not as severe as some other drugs being that the symptoms are psychological. However, these symptoms are usually accompanied by strong cravings. Ketamine can cause amnesia which may lead to overdose deaths as abusers of ketamine may not be aware of the dose of the drug which they have taken [31].

There are many drugs which are abused for a wide variety of reasons. The common denominator to understanding all forms of abuse is a knowledge of addiction. Ketamine is a drug which has been abused through the years by many individuals due to its psychological effects. Unfortunately, it has also been used on unwitting victims as a "date-rape" drug.

\section{References}

1. American Society of Addiction (2018) Definition of Addiction.

2. Vadivelu N, Schermer E, Kodumudi V, Belani K, Urman $\mathrm{RD}$, et al. (2016) Role of ketamine for analgesia in adults and children. J Anesthesiol Clin Pharmacol 32: 298-306.

3. Foundation for a Drug-Free World (2018) Ketamine.

4. Hills CE, Jin T, Siamantouras E, Liu IK, Jefferson KP, et al. (2013) 'Special K' and a loss of cell to cell adhesion in proximal tubule-derived epithelial cells: Modulation of the adherens junction complex by ketamine. PLoS One 8: e71819.
5. Solovitch S (2016) The Washington Post. Onetime party drug hailed as miracle for treating severe depression.

6. Sinner B, Graf BM (2008) Ketamine. Handb Exp Pharmaol 313-333.

7. Cromhout A (2003) Ketamine: Its use in the emergency department. Emerg Med (Fremantle) 15: 155-159.

8. Guldner GT, Petinaux B, Clemens P, Foster S, Antoine S (2006) Ketamine for procedural sedation and analgesia by nonasethesiologists in the field: A review for military health care providers. Mil Med 171: 484-490.

9. Gao M, Rejaei D, Liu H (2016) Ketamine use in current clinical practice. Acta Pharmacol Sin 37: 865-872.

10. Craven R (2007) Ketamine. Anesthesia 62: 48-53.

11. Lodge D, Anis NA, Burton NR (1982) Effects of optical isomers of ketamine on excitation of cat and rat spinal neurones by amino acids and acetylcholine. Neurosci Lett 29: 281-286.

12. Chizh BA (2007) Low dose ketamine: A therapeutic and research tool to explore n-methyl-D-aspartate (NMDA) receptor-mediated plasticity in pain pathways. J Psychopharmacol 21: 259-271.

13. Peltoniemi MA, Hagelberg NM, Olkkola KT, Saari TI (2016) Ketamine: A review of clinical pharmacokinetics and pharmacodynamics in anesthesia and pain therapy. Clin Pharmacokinet 55: 1059-1077.

14. Bonnet U, Scherbaum N (2015) Striking similarities between clinical and biological properties of ketamine and ethanol: Linking anti-depressant after effect and burgeoning addiction? J Alchol Drug Depend 3: 198.

15. Chu PS, Ma WK, Wong SC, Chu RW, Cheng $\mathrm{CH}$, et al. (2008) The destruction of the lower urinary tract by ketamine abuse: A new syndrome? BJU Int 102: 1616-1622.

16. Nomiya A, Nishimatsu $H$, Homma $Y(2011)$ Interstitial cystitis symptoms associated with ketamine abuse: The first Japanese case. Int J Urol 18: 735.

17. Poon TC, Wong KF, Chan MY, Fung KW, Chu SK, et al. (2010) Upper gastrointestinal problems in inhalational ketamine abusers. J Dig Dis 11: 106-110.

18. Fallon MT, Welsh $\mathrm{J}$ (1996) The role of ketamine in pain control. Eur J Palliative Care 3: 143-146.

19. Fisher K, Coderre TJ, Hagen NA (2000) Targeting the $\mathrm{N}$-methyl-D-aspartate receptor for chronic pain management. Preclinical animal studies, recent clinical experience and future research directions. J Pain Symptom Manage 20: 358-373.

20. Twycross R, Wilcock A, Charlesworth S, Dickman A, Thorp S (2002) Palliative Care Formulary 2. ( $2^{\text {nd }}$ edn), London: Radcliffe Medical.

21. Ketamine addiction statistics.

22. Ketamine overdose.

23. Morgan CJ, Muetzelfeldt L, Curran HV (2009) Ketamine use, cognition and psychological wellbeing: A comparison of frequent, infrequent and ex-users with polydrug and non-using controls. Addiction 104: 77-87.

24. Pappachan JM, Raj B, Thomas S, Hanna FW (2014) Multiorgan dysfunction related to chronic ketamine abuse. Proc (Byl Univ Med Cent) 27: 223-225.

25. Chakraborty K, Neogi R, Basu D (2011) Club drugs: Review of the 'rave' with a note of concern for the Indian scenario. Indian J Med Res 133: 594-604. 
26. Koesters SC, Rogers PD, Rajasingham CR (2002) MDMA ('ecstasy') and other 'club drugs'. The new epidemic. Pediatr Clin North Am 49: 415-433.

27. Yiu-Cheung $C$ (2012) Acute and chronic toxicity pattern in ketamine abusers in Hong Kong. J Med Toxicol 8: 267-270.

28. Okon T (2007) Ketamine: An introduction for the pain and palliative medicine physician. Pain Physician 10: 493-500.

29. Lo RS, Krishnamoorthy R, Freeman JG, Austin AS (2011)
Cholestasis and biliary dilatation associated with chronic ketamine abuse: A case series. Singapore Med J 52: e52-e55.

30. Wong SW, Lee KF, Wong J, Ng WW, Cheung YS, et al. (2009) Dilated common bile ducts mimicking choledochal cysts in ketamine abusers. Hong Kong Med J 15: 53-56.

31. American Addiction Centers (2018) Can Ketamine be abused and cause withdrawal? 